\title{
CITY MODELLING USING GEOINFORMATICS: A CASE STUDY OF THE COLLEGE OF ENGINEERING CAMPUS, SALAHADDIN UNIVERSITY, IRAQ
}

\author{
H. Sadeq ${ }^{*}$ \\ Geomatics Eng. Dep., College of Engineering, Salahaddin University-Erbil, Kirkuk Road, Erbil-Iraq - haval.sadeq@su.edu.krd
}

\author{
ICWG II/III: Pattern Analysis in Remote Sensing
}

\begin{abstract}
KEY WORDS: 3D City Modelling, Photogrammetry, Esri Satellite Imagery, Geoinformatics, CityEngine
\end{abstract}
\begin{abstract}
Although personal computers, smartphones and software for viewing 3D digital maps are available, online tools must be provided to aid people in different countries in visualising good locations for navigation and planning. This work presents a methodology for implementing geoinformatics to produce a 3D city model by using free rectified satellite imagery and stereo aerial imagery as data sources. Although satellite imagery has a low resolution (Thus, results will not be accurate if compared to aerial imagery.), the imagery is used to evaluate the potential of implementing such data for developing countries with limited access to data and resources. Satellite imagery with limited resolution can be used to produce models in LoD1 according to CityGML. For enhanced building details (i.e. LoD2) and an accurate 3D model, stereo aerial imagery is adopted, but this high-resolution method is costly. High-accuracy stereo aerial imagery is used to evaluate the model produced from the free satellite imagery. Finally, the results are published for online viewing.
\end{abstract}

\section{INTRODUCTION}

Maps are important in planning and navigation. For a long time, the focus was on 2D maps that provided planimetric locations of areas. However, the insufficient information provided by $2 \mathrm{D}$ maps entails the need for representing the features in $3 \mathrm{D}$ views to obtain a good understanding of the objects and their relation to the surrounding objects. These 3D city models, which represent the spatial representation of geographic information, are known as virtual geographic environments (VGEs) (Qing et al. 2009). 3D city models were originally mainly devoted to visualisation but were extended to communication and analysis. The application of city modelling is increasing dramatically, given its application in environmental and urban analysis and planning (Buhur et al. 2009, Ghassoun et al. 2015, Leszek 2015). Various benefits can be obtained from 3D city models, such as geo-visualisation, energy demand analysis, urban planning, 3D cadastre, routing and flood risk analysis. A detailed list of the field applications can be found in (Biljecki et al. 2015). Meanwhile, the development of geoinformatics includes geospatial data acquisition, storage, algorithms for manipulating geospatial databases, visualisation and spatial planning. Thus, geoinformatics is a combination of GIS, photogrammetry, remote sensing and cartography (Ehlers 2008). Furthermore, advancements in data-capturing tools, such as space, airborne images or LiDAR data, in line with the evolution of computer graphics and techniques for extracting features from data, have motivated experts to produce $3 \mathrm{D}$ models for cities.

3D city models are an active research topic, and virtual models have been produced for entire cities, such as Berlin, Germany (Döllner et al. 2006), and Konya, Turkey (Yalcin and Selcuk 2015). Different sources of data are used in 3D city modelling and mapping. Uggla (2015) evaluated LiDAR data that combined aerial images for 3D city modelling. Vosselman et al. (2015) described an algorithm for integrating 2D topographic data with 3D point clouds for obtaining 3D models. For online 3D city modelling, (Mao 2011) proposed a visualisation process and generalisation in different scales. Online 3D city modelling has been a research area for generating semi-automated approaches and creating 3D city models (Kokkas 2008). Certain countries have launched technologies for $3 \mathrm{D}$ development to form national 3D standards (Stoter et al. 2016, Stoter et al. 2011). Although the intention is to automatically extract building structures for city modelling, the technology faces the challenge posed by the complexity of buildings and use of data (Haala and Kada 2010).

An increase in the number of 3D city model applications has resulted in the development of techniques for automatically producing building structures from different data sources. [own citation] proposed an algorithm based on Bayesian approach for automatically extracting buildings from very-high-resolution satellite imagery. Sharkawi and Rahman (2014) suggested the implementation of building semantics and geometric values through segmenting for 3D modelling. The result of a 3D model was improved by combining the extracted building model with a street-level photo, and a realistic 3D model was produced based on a procedural model (MÜLler Arisona et al. 2013). 3D city modelling has become a popular topic among users, and researchers have been attempting to quickly produce city models based on information from cadastral maps (e.g. number of storeys and their height) without using elevation data (Biljecki et al. 2017).

This research focuses on extracting data from satellite or aerial imagery. First, satellite imagery is digitised manually, and then, the elevation of an object is estimated based on the building's storeys. Then, an attribute is assigned to the object, and a 3D model is produced. Afterwards, stereo aerial imageries are processed using photogrammetry with the aid of GCPs collected from the site. The objects are then extracted from the stereo parts by a stereo-digitising software, which can produce the planimetric and roof height of buildings. Finally, the software CityEngine is used to produce 3D models for both cases. Given the advantage of the web system and its highly favourable role in navigation and planning due to ease of access, the 3D city models are published online using the software Esri. 


\section{STUDY AREA}

The study area in this research is in Erbil City, northern Iraq. A region measuring approximately $650 \mathrm{~m}$ width by $700 \mathrm{~m}$ height and located in the College of engineering campus at Salahaddin University-Erbil is selected. The area has various types of buildings that have low and medium altitudes. Furthermore, some of the buildings are complex and have different levels of elevation. The area has different types of facilities that can be accessed through internal roads.

\section{METHODOLOGY}

The main items in 3D city modelling are objects represented by DTM, including buildings, trees, roads and ground construction. Attributes are assigned to the objects to generate a database, and the objects are then visualised. In this research, two datasets are launched for data acquisition, namely, satellite and stereo aerial imagery datasets.

\subsection{D Modelling from Satellite Imagery}

Providing data, such as satellite or aerial imagery in developing countries, is challenging due to resource and budget limitations for supporting such projects. Therefore, free satellite imagery that is available in ArcGIS has been used. The imagery provided by Esri is for the whole world and has a resolution of $1 \mathrm{~m}$ or better. The images are free and specified as satellite or aerial. Furthermore, low-resolution satellite images are provided worldwide (image sources: Esri, DigitalGlobe, GeoEye, Earthstar Geographics, CNES/Airbus DS, USDA, USGS, AEX, Getmapping, Aerogrid, IGN, IGP, swisstopo and the GIS User Community).

The free satellite imagery that is designated for the study area is sourced from WorldView-2, with a resolution of $0.5 \mathrm{~m}$. The imagery is orthorectified and georeferenced to the world coordinate system UTM-38N. The images can be downloaded directly from ArcGIS free of charge.

3.1.1. Objects Extraction: The objects are extracted into ArcMap from the downloaded satellite imagery. Each object is digitised individually, and an attribute (e.g. building name) is assigned to it using the ArcGIS tool. The object is subsequently saved into a shape file within the ArcGIS environment, as shown in Figure 1. Given that the imagery is georeferenced, the coordinate system of the extracted objects is directly assigned to the registered coordinate system UTM-38N. The objects are represented as vector data and extracted based on the roof of the buildings. However, although the satellite imagery is rectified for the ground and the relief is removed from the ground only, the buildings are still shown to be leaning, and the buildings still have relief. This issue has caused errors during extraction; the building is supposed to represent the base of the building and not the roof

3.1.2. Height Data for Satellite Data: Different sources of global height data are available free of charge and can be used for height measurements, such as ASTER, SRTM and ALOS. However, their data have lower accuracy (not higher than $4 \mathrm{~m}$ ) (Santillan and Makinano-Santillan 2016). This amount of error is substantial; thus, assigning the data to buildings would be difficult.

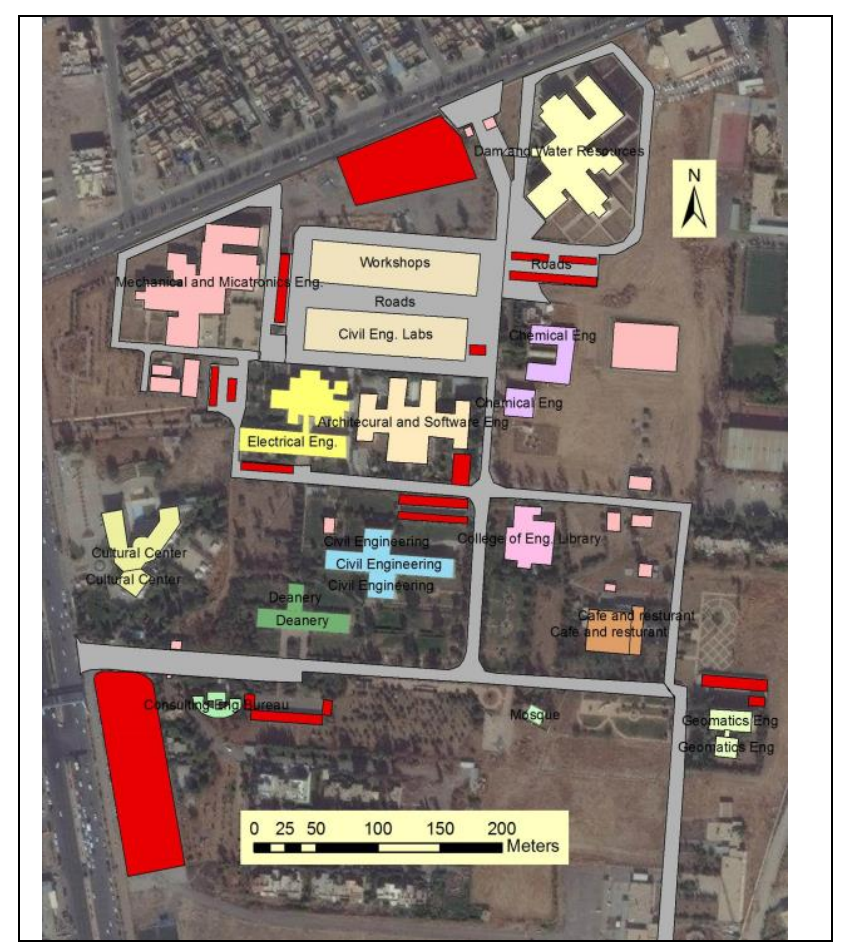

Figure 1. Digitised buildings of the study area, as shown by free world satellite imagery (image sources: Esri,

DigitalGlobe, GeoEye, Earthstar Geographics, CNES/Airbus

DS, USDA, USGS, AEX, Getmapping, Aerogrid, IGN, IGP, swisstopo and the GIS User Community).

Therefore, similar to the obtained building height in Biljecki et al. (2017), that in the current study is estimated building height is based on the number of storeys of each building, and the height of each storey is assumed.

In this research, to find the relation between the heights of a building based on the number of storeys, the heights of some buildings at the study area have been measured and then the number of storeys of each building are counted. Later, the relation between building height and number of floors is plotted as shown in Figure 2.

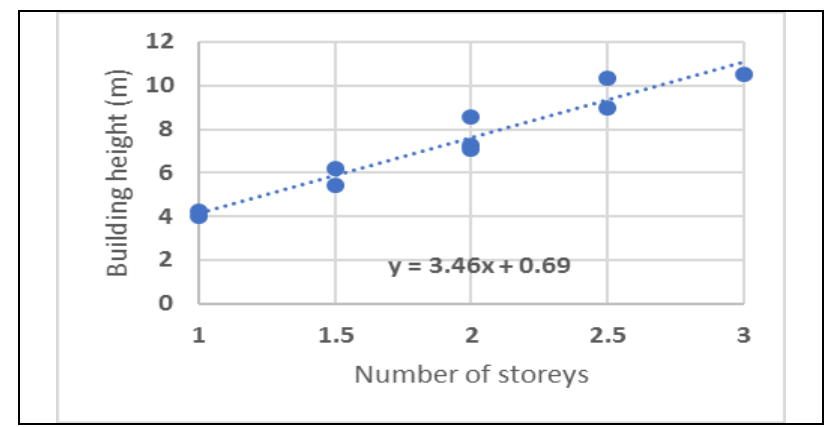

Figure 2. Relation between the number of storeys and the height of the buildings, number of storeys for some buildings are given to be 1.5 or 2.5 in the case if the Hight of the building is higher than standard. 
From the graph in Figure 2, Equation (1) is developed. It shows the trend of the number of storeys and building height for the study area. The height of each floor is approximately $3.46 \mathrm{~m}$. In addition, an absolute value of $0.69 \mathrm{~m}$ is assigned to the total building height, which is estimated as the height of the parapet on the roof of each building (Given that the roof surfaces are flat, for safety and decoration purposes, parapets should be built around the edges of the roofs.

$$
\text { H_Bldg. }=3.46 \mathrm{~N}+0.69 \text {, }
$$

where $\quad H \_B l d g=$ height of the buildings obtained in meters; $\mathrm{N}=$ number of storeys.

3.1.3. Export to CityEngine: For the 3D modelling, the terrain is imported using the CityEngine ground model that is available in the software repository. Afterwards, the buildings that are extracted in Subsection 3.1.1 are specified to have no elevation. Therefore, for 3D shape, they are extruded by using the estimated height using Equation (1). According to the definition of building details by CityGML, the shape of the obtained buildings is specified to be LoD1 (out of five levels of details [LoD0 to LoD4]) (Baig and Abdul-Rahman 2013, Biljecki et al. 2016, Breunig et al. 2015, Gröger et al. 2012, Gröger and Plümer 2012), given that only one height is assigned to the buildings, and the surface details are abandoned. The 3D model is produced using CityEngine, which can be used to produce 3D models for various areas. This software is compatible with ArcGIS; for each object, a rule can be used to create 3D objects. The rule is used to assign height and colour to each building to produce a realistic shape. The result is shown in Figure 3 . Although this method is assumed to be not fully accurate, the results could provide an overview of the area that is required to produce a 3D model using the least amount of resources.

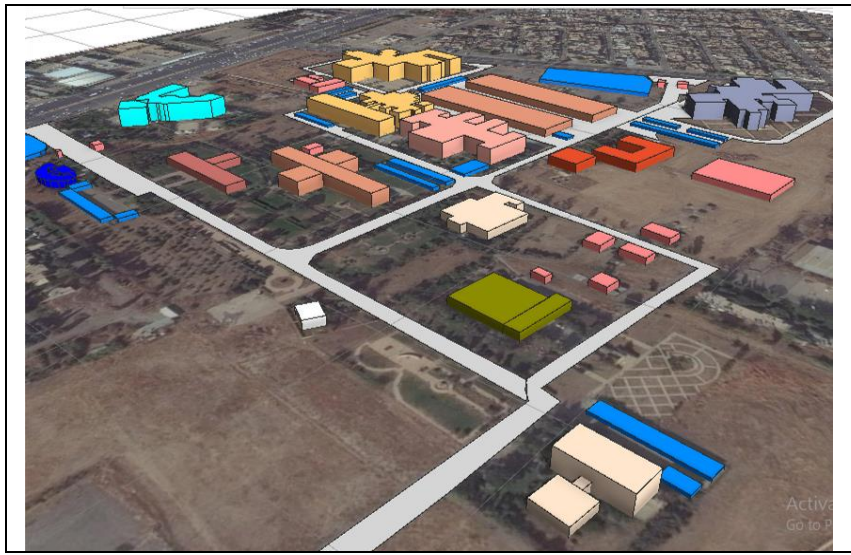

Figure 3. Free world satellite imagery showing the study area with overlying digitised buildings on the ground

\subsection{D Modelling from Stereo Aerial Imagery}

The resolution and the quality of the imagery are significant factors in generating the 3D city model with respect to accuracy, as the building feature can be identified more precisely in a high-resolution image. In this stage, the 3D city model is produced using aerial imagery via photogrammetry without including any other source of data, e.g. cadastral maps and GIS. The aerial imagery used in this research is for Erbil and captured from an altitude of $2195 \mathrm{~m}$ above ellipsoid WGS-84.
The resolution of the imagery is $10 \mathrm{~cm}$. Thus, the feature can be identified very clearly on the image by a user. The imagery can be processed with the software Summit Evolution.

3.2.1. Image Processing: For starting the measurements from the aerial imagery, the mathematical relationship between the image sensor and the ground must be determined through aerotriangulation. The goal is to orient and register the images to the ground. First, the interior orientation is obtained using the camera calibration report for an UltraCAM camera. For the exterior orientation, five GCPs are collected from the site using a differential GPS Leica-1200. The points are assigned to the projection zone UTM-38N for the planimetric coordinates and WGS84 ellipsoid for the height.

3.2.2. Stereo Digitising: Beyond the triangulation stage, the imagery is prepared for measurements. The buildings are digitised using Summit Evolution, which deals with stereo images. The main component of the $3 \mathrm{D}$ city model, which is composed of the buildings, is first extracted. Meanwhile, the other factors used to define the whole model and to provide an improved impression comprise roads, terrain and trees. The buildings are digitised using the photogrammetric stereo capability of Summit Evolution via a workstation. The software allows for digitising the buildings accurately. The operator digitises each building using stereo glasses, and the objects are exported into a shape file directly for subsequent use in $3 \mathrm{D}$ modelling. During the digitisation via photogrammetry, the roofs of the buildings are identified. Thus, in addition to the planimetric position of the feature, the height position is obtained. Thus, the data can easily be used in 3D city modelling. As shown in Figure 4, the digitised building from the stereo imagery is not located on the roof of the building; it is using both the left and the right image simultaneously. Otherwise, the image is shown at the base of the building. This feature is the advantage of using stereo imagery over one imagery (in which the buildings lean, and only part of the base appears), as in the case of the ortho satellite imagery in Section 3.1.1.

The streets are digitised, and the tree locations are identified. For the ground level of the model, a DTM is generated by measuring points on the ground every $20 \mathrm{~m}$. Only the ground points are measured manually using Summit Evolution. Afterwards, the orthophoto is generated for use in ground representation.

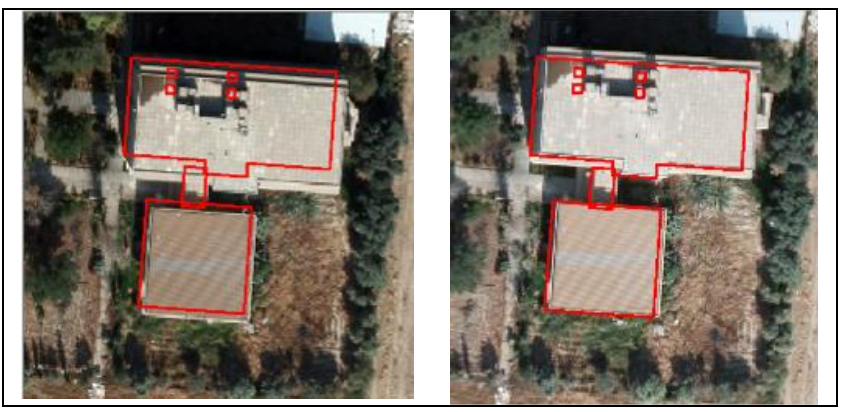

Figure 4. Processed stereo imagery showing the digitised boundary, with the building location digitised using photogrammetric software 
3.2.3. City Model Production: CityEngine is used to visualise the objects. The terrain is first created by using the generated DEM and the orthophoto from the stereo aerial imagery. Subsequently, the extracted objected is imported into CityEngine, which can import the digitised objects in SHP format. The extracted objects are imported as roof only, as seen in Figure 5 (left), which is based on the elevation of the ellipsoid WGS-84 reference system that is the same as the GCP coordinate system used in processing the aerial imagery. Then, the objects are constructed through converting the extracted buildings into solid form by using the rule in CityEngine, as shown in Figure 5 (right), which is accomplished by projecting the roof on the ground. The constructed building is LoD2 according to the CityGML definition, thereby giving the model a more details than LoD1.
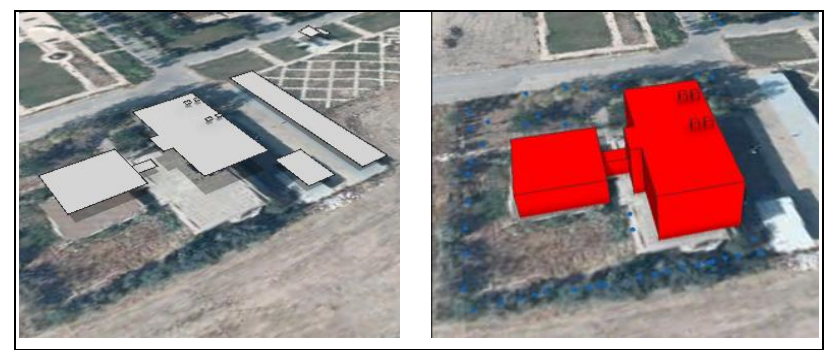

Figure 5. Imported building to CityEngine: (left) digitised building showing real elevation, (right) generated solid shape

With the high-resolution aerial imagery, a complex building can be expanded to multiple layers, as shown in Figure 6. The aerial imagery can enable access to different locations within the buildings. Even with the use of field equipment, measuring the coordinates for such point will be very intensive task due to the need to move the device to different locations. The accuracy of the extracted building is increased, as the precise building locations will be identified. This step could minimise the selection of incorrect locations.

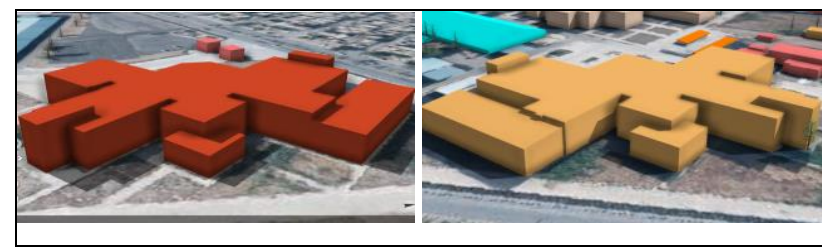

Figure 6. Two different complex buildings that are specified to be multi-layered and were produced using summit evolution software

CityEngine can also assign texture to the roofs and walls to make a realistic impression. For the texture, the imagery is captured for the facades of the buildings on the ground using a terrestrial camera. For the roofs of the buildings, images are taken by either a UAV (highly accurate) or a high-resolution aerial imagery. Using UAV imagery is preferred for the façade in addition to the roof in the case of buildings surrounded by tall trees. Such trees could obscure the buildings' facade, and taking images from the ground up would be difficult, as shown in Figure 9 (Left).

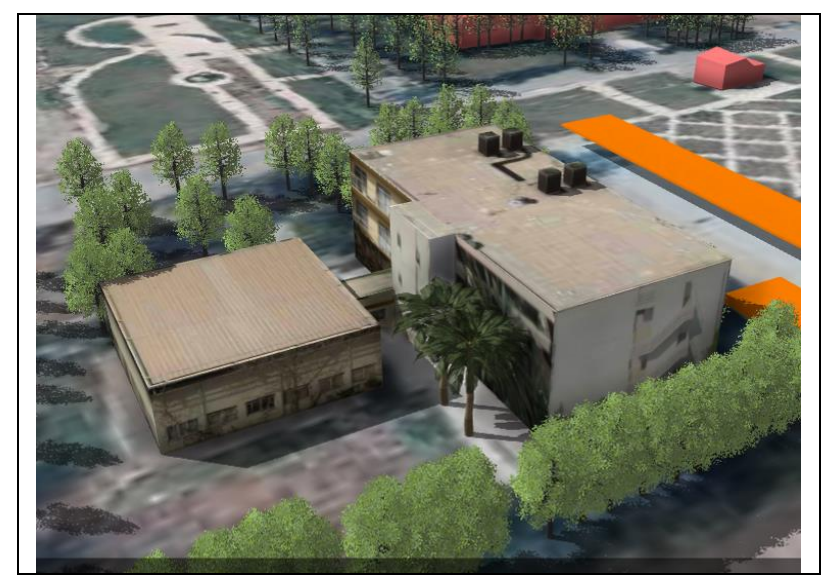

Figure 7. Assigning texture to the solid shape to obtain realistic impression

\section{PUBLISHING ONLINE}

The produced model in CityEngine can be easily uploaded online using Esri's online tools. The model can be viewed online through a web browser, as shown in Figure 8. The CityEngine web viewer does not need a plugin to be installed. The online browser can view each of the layers individually to distinguish and study each object separately. The model can be viewed on a mobile phone or on a computer screen. Publishing models online has been an important tool for widely spreading 3D models, as the method helps users view the produced models without the need to install specific software.

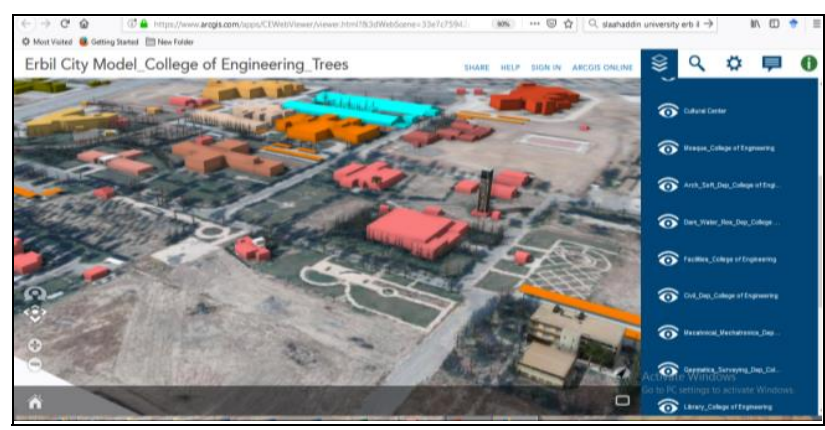

Figure 8. Online publishing of the 3D city model obtained via stereo aerial imagery

The CityEngine online viewer can help users make decisions regarding the selection of locations of new buildings or landscapes, and helps show users how shadows are casted on the ground by buildings, how shadows on the ground move during different times of the day or during different days in a year, and how shadow volume is calculated.

\section{EVALUATION}

The produced model and the constructed buildings are evaluated. In this section, qualitative and quantitative evaluation methods are applied.

\subsection{Qualitative Evaluation}

For qualitative validation, the produced building in the CityEngine models is compared with areal building. The UAV image for the building shown in Figure 9 is compared with the image of the building produced from CityEngine. The building produced from the stereo imagery clearly represents the real 
building. Even the facilities on the roof of the building are clearly displayed, which represents the detail LoD2, as shown in Figure 7. However, a comparison of the building produced from satellite imagery (Figure 9, right) shows that several details are missing on the roof of the building, and the annex is not displayed. The building is produced by extruding the footprint based on the estimated height, which means the produced model is limited to LoD1 only.
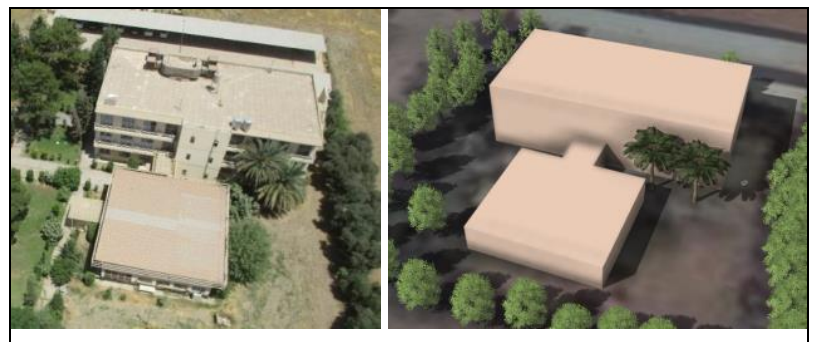

Figure 9. Left: UAV image captured from inclined view; right: image of same building produced from free satellite imagery, without textures and missing details

The qualitative assessment is extended to another building. As shown in Figure 10 (left), the building produced from the satellite imagery has very limited detail. The real building shape cannot be inferred, given that the images do not have very high resolution, and the operator cannot identify the details of the buildings, as in the case of the satellite imagery (which led only to LoD1). However, in Figure 10 (right), with enhanced resolution imagery, the details can be easily identified, and the roof of the building can easily be recognised. Thus, the level of the buildings can be extended to LoD2.

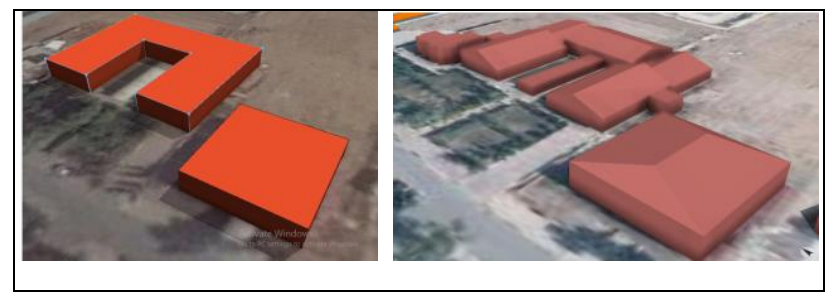

Figure 10. Two levels of details for the same buildings: (left) LoD1 from satellite imagery, (right) LoD2 from aerial imagery

\subsection{Quantitative Evaluation}

For an accurate assessment, the vector maps of the stereo aerial and satellite imagery are superimposed, as shown in Figure 11. The stereo aerial imagery is used as a base, given that it uses high-resolution data. As shown in the figure, the vector of the satellite imagery has a systematic error to the top and left directions (1.95 $\mathrm{m}$ in the east and $2.5 \mathrm{~m}$ in the north).

For evaluating the building accuracy of the satellite against stereo aerial imagery, 32 edges of the buildings are measured for different buildings scattered in the study area. The evaluation of RMSE, as shown in Equation (2), is used for the accuracy measurement.

$$
R M S E=\sqrt{\frac{1}{n} \sum d^{2}}
$$

where

$d=$ difference of the measurements of the building side produced from stereo aerial and satellite imagery; $n=$ number of measurements

The RMSE values of the objects produced from the satellite imagery are approximately $1.2 \mathrm{~m}$. For height assessment, the heights of 10 buildings are measured and compared with the heights obtained by Equation (1). The RMSE value is $0.56 \mathrm{~m}$.

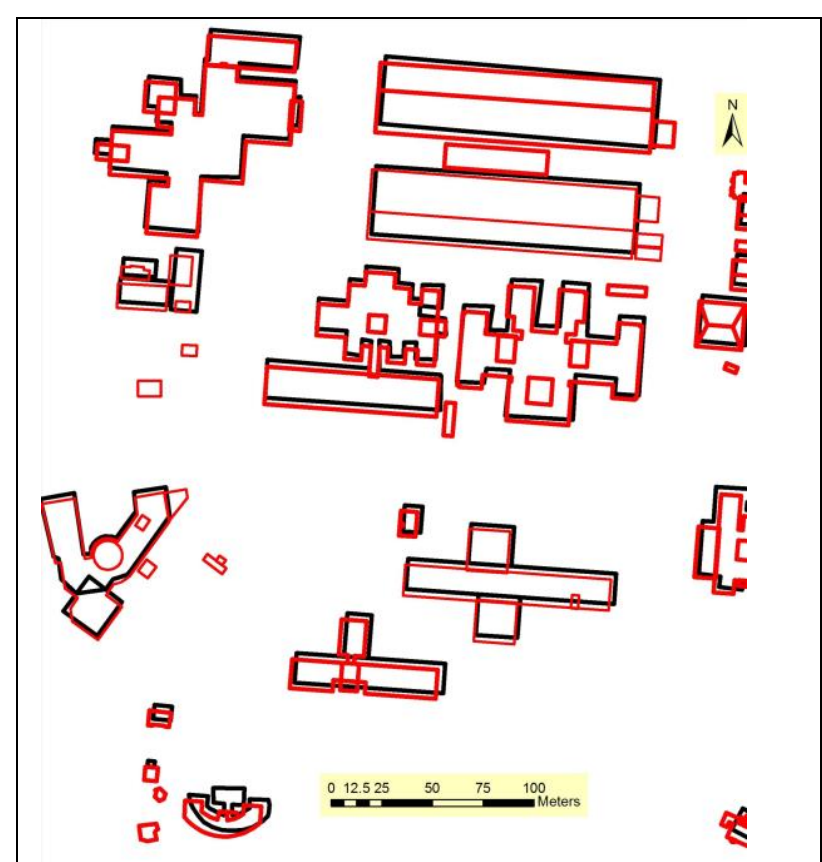

Figure 11. Vector map produced from stereo aerial vector (red) and satellite data vector (black)

\section{CONCLUSION}

This research shows the procedure of implementing geoinformatics in city modelling through manually digitising the objects using stereo aerial and free satellite imagery. The analysis shows that the quality and accuracy of objects produced from stereo aerial imagery is higher than that from satellite imagery of up to LoD2. However, in the case of countries that are not able to provide stereo aerial imagery, free satellite imagery can be used for 3D city modelling, but the level of detail is limited to only LoD1. For a realistic view, using terrestrial or UAV images can lead to a more detailed model. The accuracy of the model produced from free stellate imagery is approximately $1.2 \mathrm{~m}$ for planimetric error, and for the height using the suggested height estimation, as shown in Equation (1), this value is around $0.5 \mathrm{~m}$. CityEngine is effectively used for producing and uploading 3D models. Through a web server, users can view the model without installing specific software. Moreover, within the produced model, shadow analysis can be performed for better planning for building location and landscape design.

\section{ACKNOWLEDGMENT}

The Author would like to thank the Ministry of Municipalities and Tourism of KRG for providing the aerial imagery for this research. Moreover, the Author would like to thank Esri for providing the licenses for ArcGIS and CityEngine. 


\section{REFERENCES}

Baig, S.U., Abdul-Rahman, A., 2013. Generalization of buildings within the framework of CityGML. Geo-spatial Information Science, 16(4), 247-255. doi.org/10.1080/1009502 0.2013 .866617 .

Biljecki, F., Ledoux, H., Stoter, J., 2016. An improved LOD specification for 3D building models. Computers, Environment and Urban Systems, 59, 25-37. doi.org/10.1016/j.compenvurbsy s.2016.04.005.

Biljecki, F., Ledoux, H., Stoter, J., 2017. Generating 3D city models without elevation data. Computers, Environment and Urban Systems, 64, 1-18. doi.org/10.1016/j.compenvurbsys. 2017.01.001.

Biljecki, F., Stoter, J., Ledoux, H., Zlatanova, S., Çöltekin,A., 2015. Applications of 3D City Models: State of the Art Review. ISPRS International Journal of Geo-Information, 4(4), 2842-2889. doi.org/10.3390/ijgi4042842.

Breunig, M., Al-Doori, M., Butwilowski, E., Kuper, P.V., Benner, J., Haefele, K.H., 2015. 3D Geoinformation Science. doi.org/10.1007/978-3-319-12181-9.

Buhur, S., Ross, L., Büyüksalih, G., Baz, I., 2009. 3D city modelling for planning activities, case study: Haydarpasa train station, haydarpasa port and surrounding backside zones, Istanbul. Int. Arch. Photogramm. Remote Sens. Spat. Inf. Sci, 38, 1-6.

Döllner, J., Kolbe, T.H., Liecke,F., Sgouros,T., Teichmann, K., 2006. The virtual 3d city model of berlin-managing, integrating, and communicating complex urbaninformation, In: Proceedings of the 25th internationalsymposium on urbandata management UDMS 2006, inAalborg, Denmark, 15-17. May 2006.

Ehlers, M., 2008. Geoinformatics and digital earth initiatives: a German perspective. International Journal of Digital Earth, 1(1),17-30. doi.org/10.1080/17538940701781975.

Ghassoun, Y., Löwner, M.O., Weber, S., 2015. Exploringthe Benefits of 3D City Models in the Field of Urban Particles Distribution Modelling-A Comparison of Model Results. 193-205. doi.org/10.1007/978-3-319-12181-9_12.

Gröger, G., Kolbe, T.H., Nagel, C., Häfele, K.H., 2012. OGC city geography markup language (CityGML) encoding standard. Open Geospatial Consortium.

Gröger, G., Plümer, L., 2012. CityGML - Interoperable semantic 3D city models. ISPRS Journal of Photogrammetry and Remote Sensing, 71, 12-33. doi.org/10.1016/j.isprsjprs. 2012.04.004.

Haala, N., Kada, M., 2010. An update on automatic 3D building reconstruction. ISPRS Journal of Photogrammetry and Remote Sensing, 65(6), 570-580. doi.org/10.1016/j.isprsjprs. 2010.09.006.

Kokkas, N., 2008 An investigation into semi-automated 3D city modelling. $\mathrm{PhD}$ thesis, University of Nottingham.
Leszek, K., 2015. Environmental and Urban Spatial Analysis Based on a 3D City Model. 9157, 633-645. doi.org/10.1007/978 -3-319-21470-2 46.

Mao, B., 2011. Visualisation and generalisation of 3D City Models. PhD thesis, KTH Royal Institute of Technology.

Müller Arisona, S., Zhong, C., Huang, X., Qin, R., 2013. Increasing detail of 3D models through combined photogrammetric and procedural modelling. Geo-spatial Information Science, 16(1), 45-53. doi.org/10.1080/10095020. 2013.774102.

Zhu, Q., Hu, M., Zhang, Y. Du, Z., 2009. Research and Practice in Three-Dimensional City Modeling. Geo-spatial Information Science, 12(1). 18-24. doi.org/10.1007/s11806009-0195-z.

Santillan, J.R., Makinano-Santillan, M., 2016.Vertical Accuracy Assessment of 30-M Resolution Alos, Aster, and Srtm Global Dems over Northeastern Mindanao, Philippines. ISPRS - International Archives of the Photogrammetry, Remote Sensing and Spatial Information Sciences, XLI-B4, 149-156. doi.org/10.5194/isprsarchives-XLI-B4-149-2016.

Sharkawi, K.H., Rahman, A.A., 2014. Hybrid 3D Segmentation Technique for 3D City Models, 129-140. doi.org/10.1007/978 -3-319-03644-1_9.

Stoter, J., Ledoux, H., Zlatanova, S., Biljecki, F., 2016. Towards sustainable and clean 3D Geoinformation. 21. Münchner Fortbildungsseminar Geoinformationssysteme.

Stoter, J., Vosselman, G., Goos, J., Zlatanova, S., Verbree, E., Klooster, R., Reuvers, M., 2011. Towards a national 3D Spatial Data Infrastructure: case of the Netherlands. Photogrammetrie-Fernerkundung-Geoinformation.doi.org/10.1 127/1432-8364/2011/0094.

Uggla, G., $20153 D$ City Models-A Comparative Study of Methods and Datasets. MSc thesis, Royal Institute of Technology (KTH), Stockholm, Sweden.

Vosselman, G., Post, M., Stoter, J., Xiong, B., 2015. From Nationwide Point Clouds to Nationwide 3D Landscape Models. In: Paper Presented to the Photogrammetric Week '15, Wichmann/VDE Verlag, Belin \& Offenbach.

Yalcin, G., Selcuk, O., 2015. 3D City Modelling with Oblique Photogrammetry Method. Procedia Technology, 19, 424-431. doi.org/10.1016/j.protcy.2015.02.060. 